\title{
A genetic screen reveals a periplasmic copper chaperone required for nitrite reductase activity in pathogenic Neisseria
}

\author{
Freda E.-C. Jen, ${ }^{*}$ Karrera Y. Djoko, ${ }^{\dagger}$ Stephen J. Bent, ${ }^{\ddagger}$ Christopher J. Day, ${ }^{*}$ \\ Alastair G. McEwan, ${ }^{\dagger}$ and Michael P. Jennings*,1 \\ *Institute for Glycomics, Griffith University, Gold Coast Campus, Southport, Queensland, Australia; \\ ${ }^{\dagger}$ School of Chemistry Molecular Biosciences, University of Queensland, St. Lucia, Queensland, Australia; \\ and ${ }^{\ddagger}$ Molecular and Biomedical Science, Faculty of Sciences, University of Adelaide, Adelaide, \\ South Australia, Australia
}

\begin{abstract}
Under conditions of low oxygen availability, Neisseria meningitidis and Neisseria gonorrhoeae are able to respire via a partial denitrification pathway in which nitrite is converted to nitrous oxide. In this process, nitrite reductase (AniA), a copper $(\mathrm{Cu})$-containing protein converts nitrite to $\mathrm{NO}$, and this product is converted to nitrous oxide by nitric oxide reductase (NorB). NorB also confers protection against toxic NO, and so we devised a conditional lethal screen, using a norB mutant, to identify mutants that were resistant to nitrite-dependent killing. After random-deletion mutagenesis of $N$. meningitidis, this genetic screen identified a gene encoding a $\mathrm{Cu}$ chaperone that is essential for AniA function, AccA. Purified AccA binds one $\mathrm{Cu}$ (I) ion and also possesses a second binding site for $\mathrm{Cu}$ (II). This novel periplasmic $\mathrm{Cu}$ chaperone (AccA) appears to be essential for provision of $\mathrm{Cu}$ ions to AniA of pathogenic Neisseria to generate an active nitrite reductase. Apart from the Neisseria genus, AccA is distributed across a wide range of environmental Proteobacteria species.-Jen, F. E.-C., Djoko, K. Y., Bent, S. J., Day, C.J., McEwan, A. G., Jennings, M. P. A genetic screen reveals a periplasmic copper chaperone required for nitrite reductase activity in pathogenic Neisseria. FASEB J. 29, 3828-3838 (2015). www.fasebj.org
\end{abstract}

Key Words: meningitis $\cdot$ gonorrhea $\cdot$ denitrification

NEISSERIA GONORRHOEAE AND NEISSERIA MENINGITIDIS are closely related pathogenic species that colonize only humans. N. meningitidis (meningococcus) can be carried asymptomatically, but can also cause rapidly progressing, life-threatening meningitis and sepsis when it crosses the epithelium and enters the blood. Vaccines are available to prevent invasive meningococcal disease. N. gonorrhoeae primarily colonizes the human

Abbreviations: AccA, AniA Cu chaperone; AniA, nitrite reductase in Neisseria; BCS, bathocuproine disulfonate; COG, class of orthologous group; kan, kanamycin; KLH, keyhole limpet hemocyanin; NirK, nitrite reductase; NorB, nitric oxide reductase; orf, open reading frame; PAR, 4-(2-pyridylazo)resorcinol; $\mathrm{PCu}_{\mathrm{A}} \mathrm{C}$, periplasmic $\mathrm{Cu}_{\mathrm{A}}$ chaperone; $\mathrm{SOD}$, superoxide dismutase; SPR, surface plasmon resonance genitourinary tract, causing the sexually transmitted disease, gonorrhea, a major public health concern. The emergence of gonococcal resistance toward antibiotics has recently become a significant public health problem (1). Development of a vaccine to prevent gonorrhea is the ideal solution to this emerging public health threat.

Anaerobically induced protein A [AniA (2); previously know as Pan1 (3) ], is a nitrite reductase (NirK) that plays a key role in the biology of $N$. meningitidis and $N$. gonorrhoeae. These organisms cannot use nitrate, but can use nitrite as a terminal electron acceptor to grow anaerobically (4). AniA converts nitrite $\left(\mathrm{NO}_{2}{ }^{-}\right)$to nitric oxide (NO), which is then reduced to nitrous oxide $\left(\mathrm{N}_{2} \mathrm{O}\right)$ by nitric oxide reductase (NorB) (Fig. 1A). The gene encoding nitrous oxide reductase, nos $Z$, is a pseudogene in pathogenic Neisseria, so the denitrification pathway terminates at $\mathrm{N}_{2} \mathrm{O}$, rather than at the dinitrogen gas $\mathrm{N}_{2}(5)$. Both AniA and NorB are essential for N. gonorrhoeae biofilm formation on human cervical cells (6). The expression of AniA in N. meningitidis is up-regulated during the host infection in the bloodstream (7).

AniA is a copper $(\mathrm{Cu})$-containing NirK that has both type I and II Cu centers (8). The type II center catalyses nitrite reduction, whereas the plastocyanin-like type I center is involved in mediating electron transfer from an electron donor, which is usually a c-type cytochrome or a cupredoxin such as azurin (9). Most Gram-negative bacteria express NirK (usually called NirK) in the periplasm $(10,11)$. In contrast, AniA of pathogenic Neisseria has a long $\mathrm{N}$-terminal sequence that directs its export to the outer surface of the outer membrane, where it is anchored as a lipoprotein (12). AniA of the pathogenic Neisseria also has a long, C-terminal extension that is glycosylated (13). The localization of AniA has led to investigations of this outer membrane glycoprotein as a vaccine candidate to prevent gonococcal infections (12). This unique outer membrane localization raises questions in relation to AniA folding, export, and Cu loading and about

\footnotetext{
${ }^{1}$ Correspondence: Institute for Glycomics, Griffith University, Gold Coast Campus, Building G26, Parklands Dr., Southport, QLD, Australia. E-mail: m.jennings@griffith.edu.au

doi: 10.1096/fj.15-270751
} 


\section{$\mathrm{NO}_{2}^{-} \stackrel{\text { AniA }}{\longrightarrow} \mathrm{NO} \stackrel{\text { NorB }}{\longrightarrow} \mathrm{N}_{2} \mathrm{O} \stackrel{\text { N⿶凵śs }}{\longrightarrow} \mathrm{N}_{2}$}

B

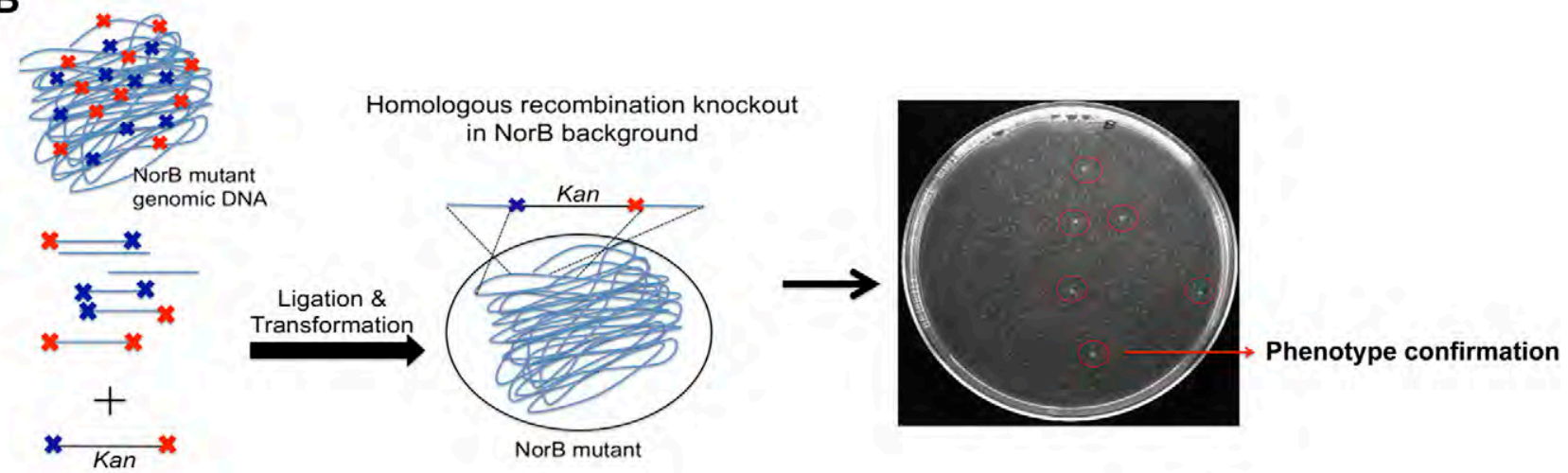

C

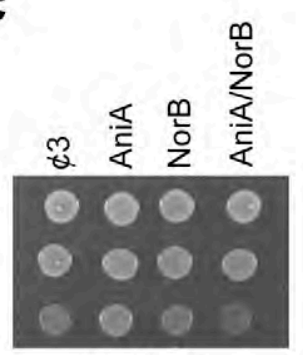

no nitrite

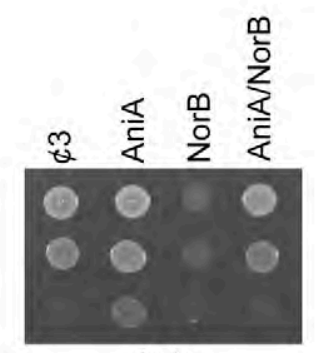

nitrite
D

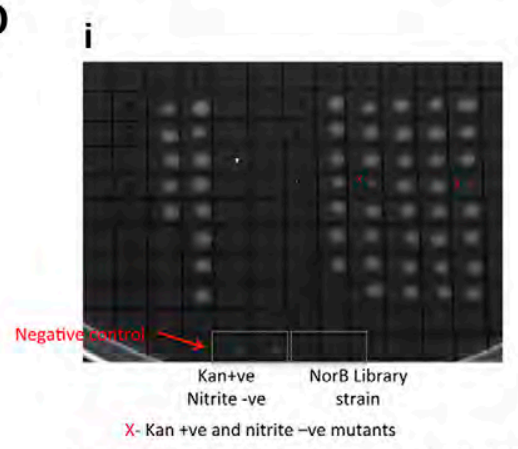

ii
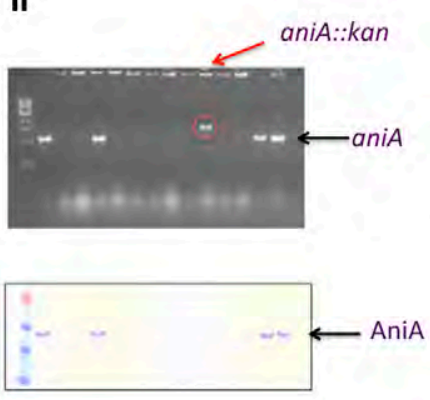

iii

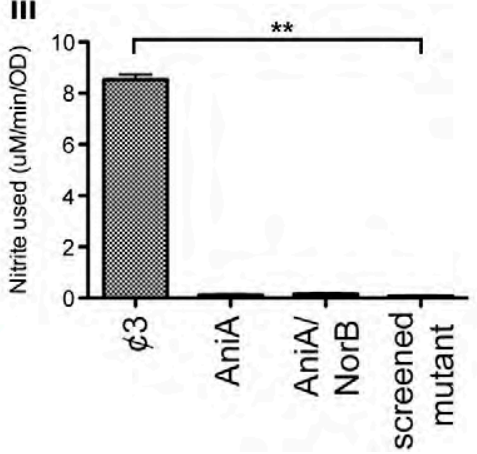

Figure 1. A) Bacterial denitrification pathway. B) Serial dilutions of bacterial growth on the media, with or without nitrite $(2 \mathrm{mM}$ $\mathrm{NaNO}_{2}$ ). C) 43 norB::tet genomic DNA and kan cassette were digested by the same set of restriction enzymes and ligated to have a mixture of random insertions of the kan cassette in NorB genomic DNA (mutagenesis library). Homologous recombination transformation of the mutagenesis library allowed the kan cassette to be randomly inserted into the NorB mutant. Over 150,000 kanamycin-resistant colonies were screened. Colonies grew on medium containing $2 \mathrm{mM} \mathrm{NaNO}_{2}$ indicating loss of AniA function. $D i)$ All the kanamycin- and nitrite-resistant colonies were picked and patched on new kanamycin $(100 \mu \mathrm{g} / \mathrm{ml}) / \mathrm{nitrite}(2 \mathrm{mM}$ $\mathrm{NaNO}_{2}$ ) plates to confirm the phenotype. Dii) To eliminate the colonies that had these phenotypes due to the loss of AniA, PCR of the aniA gene and Western blot probing with anti-AniA were performed. Diii) NirK activity assays of the screened mutant confirmed the loss of AniA activity, even when AniA protein was present. $* * P=0.001$.

the identity of its cognate electron donor on the outside of the outer membrane. The accessory proteins needed for these processes have not been defined. In this study, we used random-deletion mutagenesis and a novel screen for loss of NirK activity to identify the genes necessary for AniA function. This screen revealed a Cu chaperone that is essential for AniA activity named AniA Cu chaperone A (AccA).

\section{MATERIALS AND METHODS}

\section{Bacterial strains and growth conditions}

N. meningitidis strains $\not 3$ (14) and N. gonorrhoeae 1291 (15) were used in this study. The $N$. meningitidis strains were grown on brainheart infusion (BHI; Oxoid, Heidelberg West, VIC, Australia) $1 \%$ agar and $10 \%$ Levinthal's Medium Base at $37^{\circ} \mathrm{C}$ with $5 \% \mathrm{CO}_{2}$, 
with either kanamycin $(100 \mu \mathrm{g} / \mathrm{ml})$ or tetracycline $(5 \mu \mathrm{g} / \mathrm{ml})$, as required. $N$. gonorrhoeae strains were grown on GC agar (Oxoid) with 1\% IsoVitaleX (BD Biosciences, North Ryde, NSW, Australia).

\section{Generation of mutant strains}

N. gonorhoeae strain 1291 norB::tet and $N$. meningitidis strain $\not 3$ norB:: tet mutants were generated by a homologous recombination resulting in allelic replacement of the active gene with the inactive allele in the chromosome of these strains. The norB coding sequence (with 186 bp upstream and 494 bp downstream) was amplified from strain 1291 using primers NorBFor and NorBRev, and the resulting PCR product was cloned into pGEM-T Easy (Promega, Alexandria, NSW, Australia), to generate pGemTnorB. The pGemTnorB plasmid was digested with $B s a \mathrm{BI}$ to remove most of the norB coding sequence (1323 bp) and was replaced by a HincII-digested tet $M$ cassette from pGemtetM (16), to generate pGemTnorB::tet. The construct pGemTnorB::tet was linearized with NotI and transformed into the 1291 and $₫ 3$ strains to generate the 1291 norB::tet and $\not 3$ norB:: tet mutant strains. $N$. gonorrhoeae strain 1291 accA::kanamycin (kan) and $N$. meningitidis strain $\not 3 a c c A:: k a n$ mutants were generated by

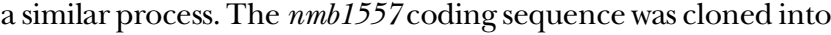
pGEMT-T Easy to generate pGemT accA. A Mutation Generation System (MGS) kit (Thermo Fisher Scientific, Scoresby, VIC, Australia) was used according to the manufacturer's instructions, to insert a transposon containing a kanR3 gene into the pGemTaccA to generate pGemT $a c c A:: k a n$. The location and orientation of the $k a n R 3$ insertion in $a c c A$ was determined by sequencing. The pGemT accA::kan construct was linearized by XmnI and transformed into strains 1291 and $₫ 3$ by homologous recombination to generate 1291 accA::kan and $₫ 3$ accA::kan mutant strains. To produce the AccA complemented version of these mutant strains, we first made 2 complementation plasmid constructs. In the first of these constructs, the $N$. meningitidis accA gene ( $\mathrm{nmb1557)}$ was amplified and cloned between $n m b 1428$ and $n m b 1429$ in plasmid pComPind (17). In the second construct, the $N$. gonorrhoeae accA gene (ngo1215) was amplified and cloned into plasmid pCTS32 (18). Plasmid pComPind $n m b 1557$ and pCTS32 ngo1215 were linearized and transformed into $\$ 3$ accA::kan and 1291 accA::kan mutants, respectively. The primers used in the processes described above are listed in Table $\mathbf{1 .}$

\section{Random mutagenesis}

The random mutagenesis method used in this study was originally described by van der Ley et al. (19). Chromosomal DNA of strain 43 norB::tet was isolated and digested with 1 of the 8 restriction enzymes: $P s t \mathrm{I}, E c o$ RI, $B s p \mathrm{HI}, P c \imath \mathrm{I}, S p h \mathrm{I}, N s p \mathrm{I}$, $S p e I$, or $X b a I$. A set (pairs selected from the 8 restriction enzymes) of digested chromosomal DNA samples was subsequently mixed and ligated to the $1.2 \mathrm{~kb}$ kanamycin-resistance marker (kan cassette) digested with the same pair of restriction enzymes (see Fig. $1 B$ ). Strain $\$ 3$ norB::tet was then transformed with the ligation mix. Kanamycin resistance was used to select for random insertion of the kan cassette into the chromosome.

\section{AccA expression and purification}

The AccA protein (amino acid residues 20-157) was amplified from $N$. meningitidis strain $\not 3$ using primers 1557NSFor_NcoI and 1557HisRev_NdeI and cloned into pET15b (NovagenEMD Biosciences, Madison, WI, USA) between the $N c o$ I and NdeI sites, to create plasmid pET15bAccAHis. This plasmid was transformed into Escherichia coli BL21 (DE3) (NEB) for overexpression. AccA was overexpressed in Luria-Bertani (LB) broth at $25^{\circ} \mathrm{C}$ for $24 \mathrm{~h}$ after addition of $0.1 \mathrm{mM}$ isopropyl- $\beta$-Dthiogalactopyranoside (IPTG). Bacteria were lysed in buffer A (50 mM Tris- $\mathrm{HCl}, 0.1 \mathrm{mg} / \mathrm{ml}$ DNaseI, and $1 \mathrm{mM} \mathrm{MgCl}_{2}$ ) via 3 passages through a French pressure cell $(15,000 \mathrm{kPa})$. AccA was purified by using TALON Metal Affinity Resin (BD Biosciences). After the sample passed through the affinity resin column, the column was washed with 10 column volumes of buffer A and 2 column volumes of buffer A with $10 \mathrm{mM}$ imidazole. The protein was eluted by collecting $1 \mathrm{ml}$ fractions over 10 column volumes of buffer A with $150 \mathrm{mM}$ imidazole. The His-tag was removed by cleavage with AcTEV Protease (Thermo Fisher Scientific, Waltham, MA, USA) prior to surface plasmon resonance (SPR) studies. The protease was removed after digestion using His-tag affinity chromatography. Removal of the His-tag from AccA was confirmed by the molecular weight shift in SDS-PAGE. After this process, the yield of AccA was sufficient for SPR analysis, but not for later Cu-binding studies.

To generate sufficient AccA protein for Cu-binding studies, we took a second approach to purifying AccA, by using its histidine-rich $\mathrm{C}$ terminus as a natural affinity tag. The acc $\mathrm{A}$ gene was amplified from $N$. meningitidis strain $\Varangle 3$ using primers accA-NdeI-F/accA-BamH1-R, cloned into vector pET-11b and then transformed into E. coli BL21 Star (DE3)pLysS (both from Novagen) for overexpression. AccA was expressed as described above and purified from crude lysates on an $\mathrm{Ni}$ (II)NTA His-Trap affinity column (GE Healthcare, Brisbane, QLD, Australia). AccA (without the synthetic His-tag) bound efficiently to the resin and was eluted with a gradient of $0-250 \mathrm{mM}$ imidazole in buffer B [50 mM Tris, $150 \mathrm{mM} \mathrm{NaCl}$, and $5 \%$

TABLE 1. Primers

\begin{tabular}{|c|c|c|}
\hline Primer & Sequence & Construct \\
\hline NorBFor & CAGAGCAGGCAAAGGCAG & pGemTnorB \\
\hline NorBRev & GAACAGCCCTACCGCATC & \\
\hline 1557ComNdeI_F & GCAGACATATGAAAAAATTATTGGCGGC & pComPind $a c c A$ \\
\hline 1557ComNsiI_R & ATTTTCATGCATTTAGTGCTGATGCGCTTC & \\
\hline $1215 \mathrm{Cmp} \_A f t \mathrm{II}$ & CAGCACCTTAAGAGAATCGTTCTCTTTG & pCST32accA \\
\hline 1215Cmp_SmaIR & TTTAAACCCGGGCATAAAAATGCCGTC & \\
\hline $1557 \mathrm{KOF}$ or & GCCGTCTGAAGGCAACGCTGTACTGGTTTTTG & pGemTaccA \\
\hline $1557 \mathrm{KORev}$ & TTCAGACGGCCAGATTAGTGCTGATGCGCTTC & \\
\hline 1557NSFor_NcoI & $\begin{array}{l}\text { CGGTTTCCATGGATGAAAGCCGGAGTCCACGTT } \\
\text { GAGGACGG }\end{array}$ & pET15bAccAHis \\
\hline 1557HisRev_NdeI & $\begin{array}{l}\text { TTTTCACATATGTTAGTGATGATGATGATGGTG } \\
\text { CTGATGCGCTTCGCCGTGGTGATGACC }\end{array}$ & \\
\hline accA-NdeI-F & CTGGAACATATGAAAAAATTATTGGCGG & pET11bAccA \\
\hline accA-BamH1-R & CAGGTAGGATCCTTAGTGCTGATGCGCTTC & \\
\hline
\end{tabular}


glycerol v/v, pH 8.2]. Fractions containing AccA were combined and treated with $5 \mathrm{mM}$ EDTA. Subsequent elution on a Superdex 75 size-exclusion column (GE Healthcare) in buffer $\mathrm{C}$ [50 mM HEPES and $150 \mathrm{mM} \mathrm{NaCl}, \mathrm{pH}$ 7.6] yielded pure AccA protein in a monomeric and unmetallated apo form. The purity of AccA preparations was $>99 \%$ as determined by SDS-PAGE. Final protein yields were $\sim 200 \mathrm{mg} / \mathrm{L}$ culture. Electrospray ionization/mass spectrometry confirmed a final protein mass of $15,161 \mathrm{Da}$, indicating that the signal peptide was cleaved correctly between $\mathrm{Ala}^{19}$ and $\mathrm{Ala}^{20}$ by the E. coli host strain. This purified AccA protein was used in Cu-binding studies. AniA protein was expressed and purified as described in Shewell et al. (12). Protein concentrations were estimated using the solution absorbance at $280 \mathrm{~nm}\left(\mathrm{e} 280-6300 \mathrm{M}^{-1} \cdot \mathrm{cm}^{-1}\right)$.

\section{Antibody production}

Polyclonal antisera, $\alpha$-AccA, were produced by inoculating mice with the peptide-conjugated keyhole limpet hemocyanin (KLH). Peptide ${ }^{32}$ KQDFLLGGSSPVADRVEVHT ${ }^{51}$ of AccA was synthesized and conjugated to KLH by Mimotopes (Clayton, VIC, Australia).

\section{SPR}

SPR experiments were performed on a Biacore T100 system (GE Healthcare) at $25^{\circ} \mathrm{C}$. Recombinant AniA protein was immobilized onto a CM5 series $\mathrm{S}$ sensor chip with an $N$-hydroxysuccinimide capture kit (GE Healthcare). This process covalently linked the AniA protein to the surface of the chip via free amine groups. The AccA protein, with and without $\mathrm{Cu}$, were run over the chip at concentrations ranging from 6.3 to $100 \mu \mathrm{g} / \mathrm{ml}$ in PBS, and the data were analyzed by using single-cycle kinetics as described by DuMont et al. (20). At least 3 experiments were performed for each interaction.

\section{Superoxide dismutase activity stain}

The superoxide dismutase (SOD) assay used in this study was originally described by Beauchamp and Fridovich (21). Cell-free extracts were prepared by resuspending cultures of $N$. meningitidis strain $\Varangle 3$, strain $\not 3$ sodC::kan, and strain $\varnothing 3$ accA:: $k a n$ in PBS overnight and then lysing the cells by TissueLyserLT (Qiagen, Chadstone Centre, VIC, Australia). Unbroken cells and cell debris were removed by centrifugation, and the supernatant was passed through a $0.45 \mu \mathrm{m}$-pore membrane filter (Millipore, North Ryde, NSW, Australia) and collected. Protein concentration in cell extracts was determined by absorbance at $280 \mathrm{~nm}$. Total proteins $(\sim 100 \mu \mathrm{g})$ from each sample was run on a Novex pH3-10 IEF protein gel (Life Technologies). After electrophoresis, the gel was soaked in solution A $[0.025 \%(\mathrm{w} / \mathrm{v})$ nitroblue tetrazolium (NBT; Sigma-Aldrich, Castle Hill, NSW, Australia) and $0.01 \%(\mathrm{w} / \mathrm{v})$ riboflavin (SigmaAldrich) in MilliQ water (Millipore)] for $20 \mathrm{~min}$ and then in solution B $[1 \%(\mathrm{w} / \mathrm{v})$ tetramethylethylenediamine (SigmaAldrich)] for $20 \mathrm{~min}$. After the gel was exposed to a light source, the SOD activity appeared as a colorless band against a purple background.

\section{Cytochrome $c b b_{3}$ oxidase activity assay}

$N$. gonorrhoeae strain 1291 and derivatives were grown in aerated BHI cultures $(50 \mathrm{ml})$ for $5 \mathrm{~h}$. The bacteria were collected by centrifugation $(4000 \mathrm{~g}, 5 \mathrm{~min})$ and washed twice with ice-cold PBS containing magnesium chloride $(10 \mathrm{mM})$. The final bacterial pellets were resuspended in the same buffer and kept on ice. Consumption of molecular oxygen was measured at $35^{\circ} \mathrm{C}$ in $\mathrm{PBS}$ $(2 \mathrm{ml})$ in the presence of sodium ascorbate $(1 \mathrm{mM})$ and $N, N, N^{\prime}$, $N^{\prime}$-tetramethylphenylenediamine $(0.2 \mathrm{mM})$ as a gratuitous electron donor to cytochrome $c b b_{3}$ oxidase. Reactions were monitored with an S1/Mini Clark-type oxygen electrode (Hansatech Instruments, King's Lynn, United Kingdom) in conjunction with an Oxytherm control unit. The rates of oxygen reduction $(1 \mathrm{U}=$ $1 \mathrm{nmol} \mathrm{O}_{2} / \mathrm{min}$ ) were plotted by using the Oxygraph Plus program (both from Hansatech), and the results were normalized to total protein content (in milligrams).

\section{Phylogenetic distribution of AccA across the bacterial domains}

The protein sequence of the accA gene from $N$. meningitidis strain $\not 3$ was used as a tblastn query against the Representative_Genomes nucleotide database from the National Center for Biotechnology (NCBI; National Institutes of Health, Bethesda, MD , USA), by using the BLAST+ command-line executable suite (22) and the BLOSUM45 matrix, with a custom output format of type 6 and the maximum target sequences set to 5000. The genomes from this database with AccA tblastn $E$ values less than 0.01 were termed positive, and the representation of positive taxa across the phylogenetic tree was used to identify groups containing positive taxa at the level of family, order, class, or phylum. To minimize any potential artifacts due to the arbitrary $0.01 E$ value cutoff, we also calculated the geometric mean of the positive $E$ value scores within each group.

To provide a backbone for representation of the distribution of accA gene homologs in bacteria, a 16S rRNA phylogenetic tree was generated. One representative from each of 23 bacterial phyla was taken for which whole genome sequences are available, plus an additional 4 representatives from the Alpha-, Beta-, Delta-, and Gammaproteobacteria classes, to represent the groups containing clear homologs of $a c c A$. We generated a maximum-likelihood tree using the GTR $+\mathrm{I}+\mathrm{G}$ substitution model in Mega 6.06 (23) and indicated on the leaf nodes the proportion of accA-positive taxa with sequenced genomes and geometric mean $E$ value from the AccA BLAST search.

\section{RESULTS}

\section{Use of a novel genetic screen to identify an essential gene for NirK activity}

It has been established that a norB mutant of Neisseria does not tolerate the presence of nitrite on the growth medium, presumably because the accumulation of NO leads to cell death (24). This lethal phenotype of the norB mutant can be suppressed by loss of AniA function (24) as shown in Fig. $1 C$. This observation allowed the development of a genetic screen in which norB mutant cells could survive only if they lost AniA activity. Construction of a kanamycin-resistant random deletion mutagenesis library in $N$. meningitidis strain $\not 3$ norB::tet, followed by selection for growth in the presence of $2 \mathrm{mM}$ nitrite, resulted in selection of kanamycin-resistant, deletion mutants with an AniAnegative phenotype (Fig. $1 C$ ).

Over 150,000 kanamycin-resistant colonies were screened on the selective media, resulting in 197 colonies that showed growth on $2 \mathrm{mM}$ nitrite. These mutants could be categorized into 2 distinct types (Fig. $1 D I, I I)$ : the first 
type ( $n=184)$ had a deletion in the aniA gene, confirmed by loss of AniA expression in Western blot analysis (Fig. 1DII). In the second type $(n=13)$, the AniA protein was expressed at wild-type levels, but this class of mutant lacked NirK activity (Fig. 1DIII). The chromosomal DNA from each of the second class of mutants (AniA expression+NirK activity) was isolated, digested with HaeII, and self-ligated. InversePCR of these self-ligated DNA fragments using outwardfacing primers, anchored in the kanamycin-resistance gene, all generated the same $\sim 2 \mathrm{kbp}$ PCR product. Sequence analysis of these PCR products revealed that the kanamycin-resistance cassette ligation event had deleted 2 genes: nmb1557 and nmb1558. According to the Kyoto Encyclopedia of Genes and Genomes (KEGG; http://www. genome.jp/kegg/), NMB1558 encodes a diacylglycerol kinase (EC: 2.7.1.107). An NCBI blast search of the NMB1557 (N. meningitidis) [or analogous $N$. gonorrhoeae open reading frame (orf); NGO1215] showed homology with a hypothetical protein found in many species that contains a class of orthologous groups (COG) domain, COG2847, which is found in $\mathrm{Cu}(\mathrm{I})$-binding proteins. Signal $\mathrm{P}$ (http://www.cbs. $d t u . d k /$ services/SignalP/, Center for Biological Sequencing Analysis, Technical University of Denmark, Lyngby, Denmark) analysis of the NMB1557 orf predicts that NMB1557 is a periplasmic protein with a N-terminal 19-amino-acid signal peptide.

\section{Cu suppresses the loss of AniA activity in mutants lacking NMB1557 and NGO1215}

Because AniA contains Cu centers types I and II (8), we hypothesized that NMB1557 (and NGO1215) is involved in the transfer of $\mathrm{Cu}$ to AniA. To investigate the role of NMB1557 (and NGO1215) in AniA function, knockout strains and the complemented versions of the knockout strains were constructed in $\not 3$ ( $\not 3$ accA::kan; $\not 3 a c c A:: k a n$ ComP) and 1291 (1291accA::kan; 1291accA::kanComP). The phenotype of these mutants was examined by growing them in selective medium and by conducting NirK assays. In nitrite-containing growth medium (Fig. 2A), nitrite had no effect on the growth of $\$ 3$ accA.::kan mutant, and the lethal phenotype of the 43 norB::tet mutant was rescued by loss of NMB1557 function ( $\$ 3$ accA:::kan/norB::tet). The NirK activity assay in Fig. $2 B$ showed that the $\not 3 a c c A:: k a n$ mutant had no NirK activity, but activity could then be restored by supplementing growth medium with excess $\mathrm{Cu}\left(5 \mu \mathrm{M} \mathrm{CuSO}_{4}\right)$, suggesting that AniA is an apo-enzyme in the $\$ 3$ accA::kan mutant strain. Some NirK activity was restored when the $\not 3 a c c A:: k a n$ strain was grown in growth medium containing $2 \mathrm{mM} \mathrm{NaNO}{ }_{2}$ and $5 \mu \mathrm{M} \mathrm{CuSO}_{4}$, resulting in a lethal phenotype (Fig 2A). The doubleknockout mutant strain, $\not 3$ accA::kan/norB::tet showed the same phenotype as the $\not 3$ norB::tet strain in this growth
Figure 2. A) Ten-fold serial dilutions of $\not 3$ and 1291 WT and mutant strains growing on the media with or without nitrite $\left.(2 \mathrm{mM} \mathrm{NaNO})_{2}\right)$ and with or without $\left.\mathrm{Cu}(5 \mu \mathrm{M} \mathrm{CuSO})_{4}\right)$. $B)$ NirK activity assays of $\varnothing 3$ and $1291 \mathrm{WT}$ and knockout mutants (AniA and AccA) strains. AccA mutant strain growing on Cu-supplemented media had a restored AniA activity. $* * P=0.0013$; $* * * P<0.0001$. The expressions of AniA and AccA were confirmed by Western blot analysis.
A

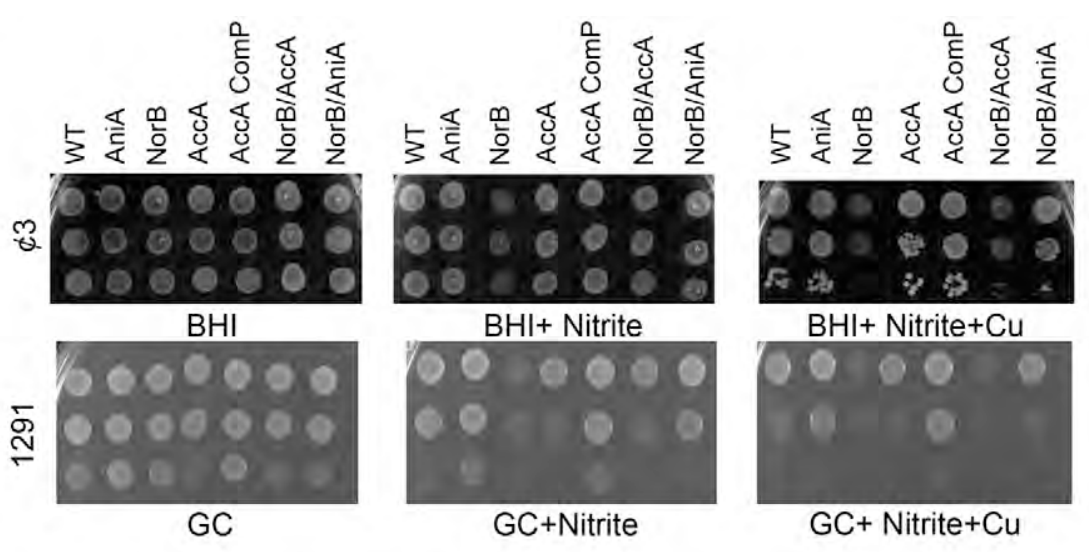

B

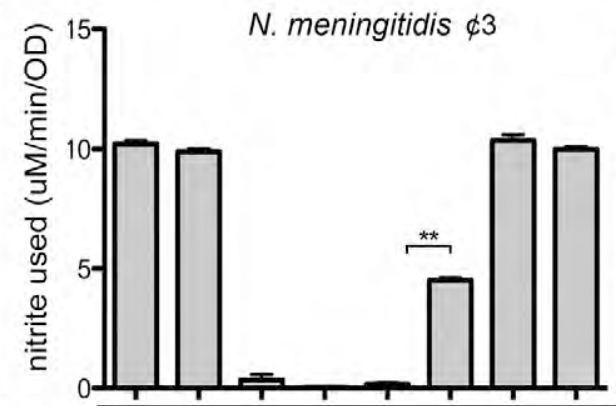

a AniA

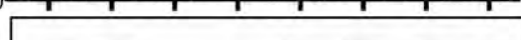

$\alpha \operatorname{Acc} A$
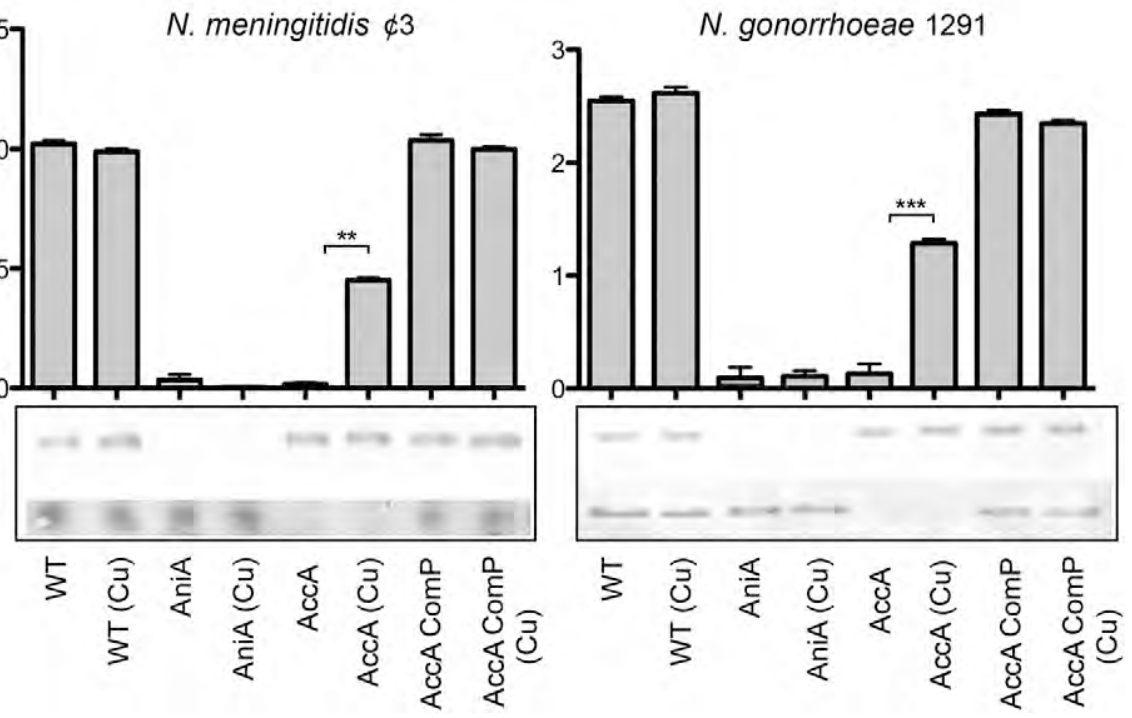
condition. Parallel studies in N. gonorrhoeae 1291 revealed that the same NMB1557 (called NGO1215 in strain 1291; $98 \%$ identity) chaperone is also necessary for AniA function in N. gonorrhoeae. In view of these results NMB1557 and NGO1215 were named AniA Cu chaperone A (AccA).

\section{AccA has a direct interaction with AniA}

It is clear that AniA requires AccA for NirK activity and that exogenous $\mathrm{Cu}$ can complement the absence of AccA in AniA function. To determine whether AccA can deliver $\mathrm{Cu}$ ions through a direct interaction with AniA, SPR was used. Recombinant AccA and AniA were expressed and purified. AniA protein was immobilized onto a series $\mathrm{S}$ sensor chip CM5. The binding affinity $\left(K_{\mathrm{d}}\right)$ of AccA (without $\mathrm{Cu})$ to AniA from triplicate experiments was $3.00 \pm 0.61 \mu \mathrm{M}$ (Table 2). The sensogram in Fig. 3 shows that AccA without $\mathrm{Cu}$ (as shown in the blue curve) associated and dissociated slowly from AniA. The off rate of this interaction (the disassociation rate in inverse time, $k_{\text {off }}$ ) was $9.49 \times 10^{-10} \pm 4.1 \times$ $10^{-10}(1 / \mathrm{s})$. The proposed function of AccA is to deliver $\mathrm{Cu}$ to AniA. The red curve in the sensogram in Fig. 3 shows that in the present of $\mathrm{Cu}$, the response unit dropped significantly after AccA and AniA association. With $\mathrm{Cu}$, the $K_{\mathrm{d}}$ of AccA to AniA was $2.13 \pm 1.2 \mu \mathrm{M}$, but it had a much faster on and off rate $\left[k_{\text {on }}=0.0005(1 / \mathrm{ms})\right.$ and $k_{\text {off }}=0.004$ (1/s); Table 2]. This result suggests that after AccA loading Cu to AniA, it rapidly dissociates from AniA. Other metals, $\mathrm{Zn}, \mathrm{Co}, \mathrm{Fe}$, and Mn, were also tested, and none of them had effects similar to $\mathrm{Cu}$ in binding AccA to AniA (Table 2).

\section{The role of AccA in SodC and cytochrome $\operatorname{cbb}_{3}$ oxidase function}

Apart from AniA, both pathogenic Neisseria species possess a cytochrome $c b b_{3}$ oxidase that contains a $\mathrm{Cu}_{\mathrm{B}}$ center, but not a $\mathrm{Cu}_{\mathrm{A}}$ center (25), whereas $N$. meningitidis possesses SodC, a periplasmic SOD protein that contains a type II Cu center (26). To examine whether AccA is also associated with the protein function of SodC, an SOD assay was performed (27). Strains N. meningitidis $\not 3, \not 3$ accA $:: k a n$, and $\not 3$ SodC::kan were examined, and the results showed that SodC activity remained in $\not 3$ accA::kan (Fig. 4A). On the other hand, compared to the wild-type strain, the 1291 accA::kan mutant displayed a small and reproducible decrease in the activity of cytochrome $c b b_{3}$ oxidase (Fig. $4 B$ ). The activity of this oxidase in the complemented strain returned to wild-type levels. This result indicates that AccA is not essential, but it does have an effect on the assembly of the $\mathrm{Cu}_{\mathrm{B}}$ center in this oxidase.

\section{Homology modeling predicts that AccA contains a $\mathrm{Cu}(\mathrm{I})$ center}

The amino acid sequence of AccA was used as a template for homology modeling with Swiss-Model ( $h t t p: / /$ swissmodel.expasy.org/; Swiss Institute of Bioinformatics, Basel, Switzerland) (28) to conduct a library search of experimental protein structures to identify suitable templates. Two structurally homologous proteins of AccA with known structures were found: TTHA1943 and DR1885. TTHA1943 from Thermus thermophilus, donates $\mathrm{Cu}(\mathrm{I})$ ions to subunit II of the cytochrome $b a_{3}$ oxidase (Cox2) to generate a functional $\mathrm{Cu}_{\mathrm{A}}$ center (29). DR1885 from Deinococcus radiodurans, is predicted to have a role in delivering $\mathrm{Cu}$ (I) to the $\mathrm{Cu}_{\mathrm{A}}$ center of cytochrome $c$ oxidase (30). The modeled structure, as shown in Fig. 5, revealed that AccA should contain a $\mathrm{Cu}(\mathrm{I})$ binding site through the conserved methionine and histidine motif $\mathrm{HX}^{10} \mathrm{MX}^{22} \mathrm{HXM}$.

\section{AccA is a $\mathrm{Cu}(\mathrm{I})$ - and $\mathrm{Cu}(\mathrm{II})$-binding protein}

The AccA protein was purified in its apo-form (see Materials and Methods), as determined by metal analyses using excess 4-(2-pyridylazo) resorcinol (PAR) as a colorimetric ligand for $\mathrm{Cu}(\mathrm{II}), \mathrm{Co}(\mathrm{II}), \mathrm{Mn}(\mathrm{II}), \mathrm{Ni}(\mathrm{II})$, and $\mathrm{Zn}(\mathrm{II})\left(\lambda_{\max }\right.$, $450-550 \mathrm{~nm}$ ), in denaturing conditions (8 M urea). Incubation of apo-AccA with $4 \mathrm{M}$ equivalents of $\mathrm{CuCl}_{2}$ in the presence of 100 equivalents of sodium ascorbate, followed by elution on a PD-10 desalting column, led to the isolation of a metallated form. $\mathrm{Cu}$ analyses using excess bathocuproine disulfonate (BCS) as a colorimetric ligand for $\mathrm{Cu}(\mathrm{I})\left(\lambda_{\max }, 483 \mathrm{~nm}\right.$; $\left.\mathrm{e}_{483}, 13,000 \mathrm{M}^{-1} \cdot \mathrm{cm}^{-1}\right)$ (31) in denaturing conditions detected $1.00 \pm 0.06$ equivalent of bound $\mathrm{Cu}(\mathrm{I})$ (Table 3). Addition of ascorbate to reduce any bound $\mathrm{Cu}(\mathrm{II})$ led to an increase in the $\mathrm{Cu}$ stoichiometry $[\mathrm{Cu}(\mathrm{I})+\mathrm{Cu}(\mathrm{II})]$ to $2.0 \pm 0.1$. These results indicate that AccA possesses 2 binding sites, 1 for $\mathrm{Cu}(\mathrm{I})$ and 1 for $\mathrm{Cu}(\mathrm{II})$. apo-AccA was also metallated by $\mathrm{Zn}(\mathrm{II})(\sim 1$ equivalent), $\mathrm{Ni}(\mathrm{II})$ ( $\sim 1$ equivalent $), \mathrm{Co}(\mathrm{II})(\sim 0.5$ equivalent $)$, or $\mathrm{Mn}$ (II) ( $\sim 0.5$ equivalent), as determined by metal analyses with PAR, against concentration standards (Table 4). However, these metal ions were unable to compete with

TABLE 2. Kinetics and affinity analysis of AccA for binding to AniA

\begin{tabular}{lcc}
\hline \hline Binding to AniA \pm metal & $K_{\mathrm{d}}(\mathrm{M})^{a}$ & $k_{\text {off }}(1 / \mathrm{s})^{b}$ \\
\hline AccA & $3.00 \times 10^{-06} \pm 6.1 \times 10^{-07}$ & $9.49 \times 10^{-06} \pm 4.1 \times 10^{-10}$ \\
AccA + Cu & $2.13 \times 10^{-06} \pm 1.2 \times 10^{-06}$ & $4.01 \times 10^{-03} \pm 1.4 \times 10^{-05}$ \\
AccA + Co & $9.87 \times 10^{-06} \pm 1.3 \times 10^{-06}$ & $1.21 \times 10^{-06} \pm 6.2 \times 10^{-07}$ \\
AccA + Fe & $6.27 \times 10^{-05} \pm 2.2 \times 10^{-05}$ & $\mathrm{ND}$ \\
AccA + Zn & $1.86 \times 10^{-04} \pm 2.4 \times 10^{-05}$ & $\mathrm{ND}$ \\
AccA $+\mathrm{Mn}$ & No binding & - \\
\hline
\end{tabular}

${ }^{a}$ Affinity of the interaction. ${ }^{b}$ Disassociation rate in inverse time. ND, not determined [Biacore software (GE Healthcare) could not uniquely determine the off rate, because it was outside the range of detection (less than $\left.1 \times 10^{-10}\right)$ ]. 
Figure 3. The binding affinity of AccA to AniA protein was measured by SPR. Blue curve: binding of apo-AccA to apo-AniA in PBS. Without $\mathrm{Cu}$, AccA bound to AniA and did not dissociate after binding. Red curve: binding of apo-AccA to apo-AniA in PBS with $25 \mathrm{mM}$ $\mathrm{CuSO}_{4}$. In the presence of $\mathrm{Cu}$, AccA bound to AniA and dissociated after binding.

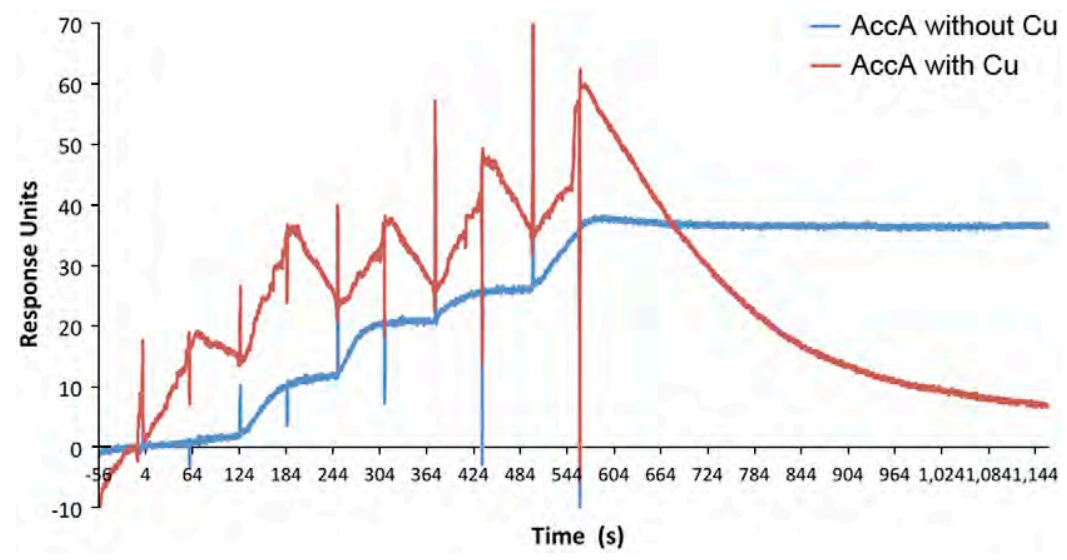

and replace bound $\mathrm{Cu}(\mathrm{I})$ or $\mathrm{Cu}(\mathrm{II})$ in AccA, suggesting that $\mathrm{AccA}$ is a $\mathrm{Cu}$-specific binding protein.

\section{Phylogenetic distribution of AccA across the bacterial domain}

At the phylum level, homologs for AccA were found across the Proteobacteria, and in Actinobacteria, Aquificae, Chlorobi, Chloroflexi, Deinococcus-Thermus, and Gemmatimonadetes. There were also patterns of representation at the family, class, and order levels within the Aquificae, Epsilonproteobacteria, Chloroflexi, and Gammaproteobacteria (Fig. 6A; Table 5), with Aquificaceae, Campylobacteraceae, non-Dehaloccoides (in Chloroflexi), and non-Enterobacteriaceae (in Gammaproteobacteria) containing all of the positive species in those phyla. In summary, some pathogenic bacteria such as Pseudomonas aeruginosa, Burkholderia pseudomallei, Bordetella parapertussis, and Bordetella pertussis contain AccA homologs; however, most strains containing AccA homologs are

A

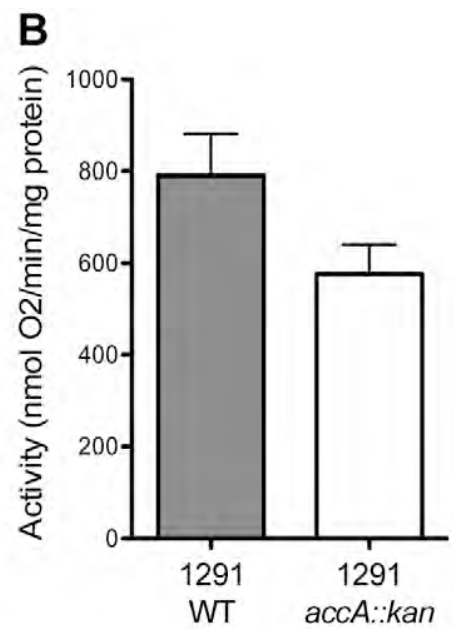

Figure 4. A) Detection of $\mathrm{Cu} / \mathrm{Zn}$ Sod activity showed that SodC activity was not affected by the loss of AccA. B) A cytochrome $c b b_{3}$ oxidase activity assay showed that AccA was not essential, but that it had an effect on the assembly of the $\mathrm{Cu}_{\mathrm{B}}$ center in this oxidase. environmental bacteria, especially the diazotrophic bacteria, such as Azospirillum lipoferum, Rhizobium, and Azotobacter vinelandii.

AccA has a structural homology with TTHA1943 in T. thermophilus; however, it differs from this cytochrome $c$ oxidase $\mathrm{Cu}$ chaperone, in that TTHA1943 does not have a C-terminal histidine rich $\mathrm{Cu}$ (II) binding site. A multiple alignment of AccA homologs is shown in Fig. 6B. All these homologs from different bacteria contain an N-terminal signal peptide (sequence underlined, predicted using Signal P), a conserved $\mathrm{Cu}(\mathrm{I})$-binding site (red box) and a C-terminal $\mathrm{Cu}(\mathrm{II})$-binding site (blue box). This alignment suggests that, apart from Neisseria, AccA is a common $\mathrm{Cu}$ chaperone found in a diverse range of bacteria. Furthermore, these predicted $\mathrm{Cu}$ chaperone homologs may have the same role as AccA.

\section{DISCUSSION}

$\mathrm{Cu}$ is a key redox center in enzymes involved in aerobic respiration, as well as a variety of reactions involving molecular oxygen (32). However, it is also a highly toxic metal ion that can exert its toxicity, either via promotion of oxidative stress or insertion into sites that normally would be occupied by other transition metal ions $(33,34)$. These biochemical properties have driven the evolution of complex pathways of $\mathrm{Cu}$ handling in both eukaryotic and prokaryotic cells, to avoid the toxic effects of this metal ion (35). These functions include the regulation of $\mathrm{Cu}$ movement across membranes via P-type ATPases and the control of $\mathrm{Cu}$ transfer between proteins via the use of Cu-binding proteins (chaperones) $(35,36)$. In prokaryotes, the focus of research has been the biogenesis of the $\mathrm{Cu}$ centers associated with respiratory enzymes of the heme-Cu oxidase superfamily (37) or on the Cu tolerance system (Cue) that protects the cell against excess $\mathrm{Cu}(38)$. In addition to its ability to catalyze reactions involving molecular oxygen, $\mathrm{Cu}$ is involved in reactions with nitrogen oxides, and 2 of the enzymes involved in denitrification are Cu enzymes: nitrous oxide reductase and NirK, the subject of the current study.

In this work, we identified a gene encoding a Cu chaperone, AccA, that is necessary for the biogenesis of functional NirK. From homology modeling, it appears that AccA has a $\mathrm{Cu}(\mathrm{I})$ center that is very similar to that described 
AccA 1 TTHA1943 1

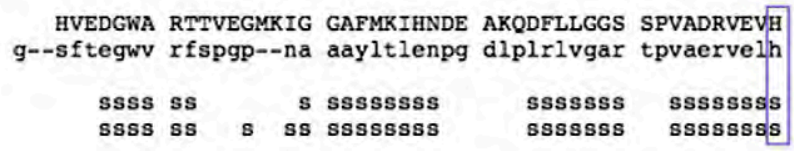

AccA 48 TTHA1943 47

AccA 94 TTHA1943 96

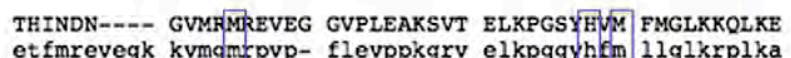
etfmrevegk kvmgmrpvp- flevppkgrv elkpggyhfm liglkrplka

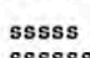
sssssss
ssssiss sss sss
sss sss ss sss ss sssps ssss sqsis ssss

GDKIPVTLKF KNAKAQTVQL EVKIA geeveldlif aggkvlkvvl pvear-

sssussss $\mathrm{s}$ ssssss ss ssssssss $s$ sssiss

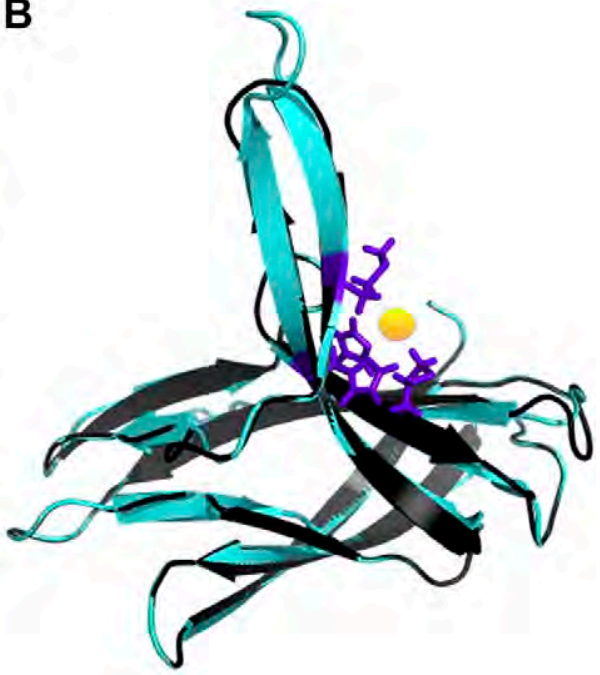

Figure 5. The structure of AccA, modeled by Swiss-Model. A) Secondary structure alignment with a known Cu(I) chaperone, TTHA1943, from T. thermophilus. Purple boxes: binding motif of $\mathrm{Cu}(\mathrm{I})$. B) Modeled AccA 3D structure (gray) aligns to the TTHA1943 Cu(I) chaperone. Yellow: $\mathrm{Cu}(\mathrm{I})$; purple: binding motif.

in TTHA1943 from T. thermophilus (30) and DR1885 from $D$. radiodurans $(30)$, in that the $\mathrm{Cu}(\mathrm{I})$-coordinating amino acids found in DR1885 (2 Met, 2 His) are conserved in AccA. Banci et al. (30) have demonstrated biochemically that DR1885 from D. radiodurans donates $\mathrm{Cu}(\mathrm{I})$ to a watersoluble apo- $\mathrm{Cu}_{\mathrm{A}}$ fragment of the CoxII protein of the cytochrome $b a_{3}$ oxidase from the same bacterium leading to the assembly of a $\mathrm{Cu}_{\mathrm{A}}$ center. For this reason, it was named the periplasmic $\mathrm{Cu}_{\mathrm{A}}$ chaperone $\left(\mathrm{PCu}_{\mathrm{A}} \mathrm{C}\right)$. However, our data show for the first time that a structural analog protein of $\mathrm{PCu}_{\mathrm{A}} \mathrm{C}, \mathrm{AccA}$, has an essential role in the assembly of an active nitrite reductase in pathogenic Neisseria, suggesting that there may be more diverse functions for this family of $\mathrm{Cu}$ chaperones in the periplasm of Gram-negative bacteria. In the case of $N$. gonorrhoeae, we observed that mutation of accA led to a small but significant effect on cytochrome oxidase activity. Because $N$. gonorrhoeae contains only cytochrome $c b b_{3}$, it can be concluded that AccA may also enhance the efficiency of the biogenesis of the heme-Cu center, but it is not essential. Pathogenic Neisseria lack cytochrome $a a_{3}$ and do not express a functional nitrous oxide, and so it was not possible to determine whether AccA is involved in the assembly of the $\mathrm{Cu}_{\mathrm{A}}$ center in this bacterium. Given the established role of $\mathrm{PCu}_{\mathrm{A}} \mathrm{C}$ in $\mathrm{Cu}_{\mathrm{A}}$ assembly in cytochrome oxidases that possess this redox center, it would be interesting to test its role in commensal Neisseria species that possess a functional nitrous oxide reductase.

AccA did not appear to be essential for assembly of SodC in N. meningitidis, although our assay would not allow us to determine whether there was a small effect on activity. The aniA ${ }^{-}$phenotype could be suppressed by addition of excess $\mathrm{Cu}$, and similar observations have been made with regard to the biochemical suppression of mutations that affect the transfer of $\mathrm{Cu}$ to cytochrome oxidase in yeast (39). This finding suggests that a $\mathrm{Cu}$ chaperone is not obligatory for the biogenesis of $\mathrm{Cu}$ centers, but it is necessary in some cases at physiologically relevant $\mathrm{Cu}$ concentrations. The observation that mutation of $\mathrm{PCu}_{\mathrm{A}} \mathrm{C}$ in Bradyrhizobium led to restricted

TABLE 3. Cu analyses of AccA

\begin{tabular}{|c|c|c|c|c|c|c|c|c|}
\hline \multirow[b]{2}{*}{ No. } & \multirow[b]{2}{*}{$\mathrm{Abs}_{280}$} & \multirow[b]{2}{*}{ AccA $(\mu \mathrm{M})$} & \multicolumn{2}{|c|}{$\mathrm{Abs}_{483}$} & \multirow[b]{2}{*}{$\mathrm{Cu}^{\mathrm{I}}(\mu \mathrm{M})$} & \multirow[b]{2}{*}{$\mathrm{Cu}^{\mathrm{I}}+\mathrm{Cu}^{\mathrm{II}}(\mu \mathrm{M})$} & \multirow[b]{2}{*}{$\mathrm{Cu}^{\mathrm{I}} / \mathrm{AccA}^{a}$} & \multirow[b]{2}{*}{$\left(\mathrm{Cu}^{\mathrm{I}}+\mathrm{Cu}^{\mathrm{II}}\right) /(\mathrm{AccA})^{b}$} \\
\hline & & & - asc & +asc & & & & \\
\hline 1 & 0.147 & 17.1 & 0.222 & 0.451 & 17.1 & 34.7 & 1.0 & 2.0 \\
\hline 2 & 0.203 & 23.6 & 0.271 & 0.603 & 20.8 & 46.4 & 0.9 & 2.0 \\
\hline 3 & 0.153 & 17.8 & 0.235 & 0.472 & 18.1 & 36.3 & 1.0 & 2.0 \\
\hline 4 & 0.109 & 15.6 & 0.194 & 0.416 & 14.9 & 32.0 & 1.0 & 2.0 \\
\hline 5 & 0.135 & 19.3 & 0.241 & 0.529 & 18.5 & 40.7 & 1.0 & 2.1 \\
\hline 6 & 0.095 & 13.6 & 0.178 & 0.394 & 13.7 & 30.3 & 1.0 & 2.2 \\
\hline 7 & 0.116 & 13.4 & 0.181 & 0.321 & 13.9 & 24.7 & 1.0 & 1.8 \\
\hline 8 & 0.131 & 15.2 & 0.203 & 0.397 & 15.6 & 30.5 & 1.0 & 2.0 \\
\hline 9 & 0.110 & 12.7 & 0.177 & 0.334 & 13.6 & 25.7 & 1.1 & 2.0 \\
\hline
\end{tabular}

Apo-AccA was incubated with $\mathrm{CuCl}_{2}(4 \mathrm{M}$ equivalent) and sodium ascorbate (100 M equivalent) and desalted. Metal analyses were performed with BCS. asc, sodium ascorbate. ${ }^{a}$ Average $\mathrm{Cu}^{\mathrm{I}} / \mathrm{AccA}=1.00 \pm 0.06$. ${ }^{b}$ Average $\mathrm{Cu}^{\mathrm{I}}+\mathrm{Cu}^{\mathrm{II}} / \mathrm{AccA}=2.0 \pm 0.1$. 


\begin{tabular}{|c|c|c|c|c|c|c|c|}
\hline \multirow[b]{2}{*}{$\mathrm{M}^{\mathrm{II} a}$} & \multirow[b]{2}{*}{ No. } & \multirow[b]{2}{*}{$\operatorname{Abs}_{280}{ }^{b}$} & \multirow[b]{2}{*}{$\operatorname{AccA}\left(\mu \mathrm{M}^{c}\right)$} & \multirow[b]{2}{*}{$\mathrm{Abs}_{500}$} & \multirow[b]{2}{*}{$\mathrm{M}^{\mathrm{II}}\left(\mu \mathrm{M}^{d}\right)$} & \multicolumn{2}{|c|}{$\mathrm{M}^{\mathrm{II}} / \mathrm{AccA}$} \\
\hline & & & & & & Each & Average \\
\hline \multirow[t]{3}{*}{$\mathrm{Zn}$} & 1 & 0.423 & 6.1 & 0.589 & 5.3 & 0.88 & \\
\hline & 2 & 0.529 & 7.6 & 0.699 & 6.3 & 0.83 & $0.87 \pm 0.04$ \\
\hline & 3 & 0.406 & 5.8 & 0.586 & 5.3 & 0.91 & \\
\hline \multirow[t]{3}{*}{ Co } & 1 & 0.425 & 6.1 & 0.181 & 2.2 & 0.36 & \\
\hline & 2 & 0.530 & 7.6 & 0.257 & 3.1 & 0.41 & $0.39 \pm 0.03$ \\
\hline & 3 & 0.400 & 5.7 & 0.189 & 2.3 & 0.40 & \\
\hline \multirow[t]{3}{*}{$\mathrm{Ni}$} & 1 & 0.415 & 5.9 & 0.578 & 5.9 & 0.99 & \\
\hline & 2 & 0.525 & 7.5 & 0.702 & 7.2 & 0.95 & $0.97 \pm 0.02$ \\
\hline & 3 & 0.409 & 5.9 & 0.551 & 5.6 & 0.96 & \\
\hline \multirow[t]{3}{*}{ Mn } & 1 & 0.416 & 6.0 & 0.067 & 3.3 & 0.55 & \\
\hline & 2 & 0.531 & 7.6 & 0.062 & 3.1 & 0.40 & $0.49 \pm 0.08$ \\
\hline & 3 & 0.411 & 5.9 & 0.063 & 3.1 & 0.53 & \\
\hline
\end{tabular}

Apo-AccA was incubated with various metal ions and desalted. Metal analyses were performed using PAR. ${ }^{a}$ Metal ions ( $>2 \mathrm{M}$ equivalent) were provided as the chloride or nitrate salts. ${ }^{b}$ AccA were diluted 10 times for analyses. The absorbance values were of the original (concentrated) stock. ${ }^{c}$ Concentrations of AccA (diluted). ${ }^{d}$ Approximate metal concentrations from a standard curve.

growth under conditions of $\mathrm{Cu}$ limitation is consistent with a role for this protein in efficient delivery of Cu to key respiratory oxidases $(40)$.

Although there is a strong structural similarity between $\mathrm{PCu}_{\mathrm{A}} \mathrm{C}$ and $\mathrm{AccA}$, AccA also has a histidine-rich region at the $\mathrm{C}$ terminus, this additional histidine-rich region may explain why it is able to bind a $\mathrm{Cu}(\mathrm{II})$ ion in addition to a $\mathrm{Cu}(\mathrm{I})$ ion. It is interesting that periplasmic SodC, also possesses a histidine-rich region that may be involved in the capture of $\mathrm{Cu}$ for biogenesis of the type II Cu site (41). This observation leads us to suggest that the primary structural and biochemical differences between $\mathrm{AccA}$ and $\mathrm{PCu}_{\mathrm{A}} \mathrm{C}$ indicate functional differences in their roles, with AccA having evolved to have a specific role in one or both of the Cu centers in NirK.

Production of reactive nitrogen species is one of the host defenses against pathogens. In N. gonorrhoeae, anaerobic metabolism of nitrite and NO is particularly important in colonization of the mucosal surface and may have led to the location of AniA at the bacterial surface. The unique location of AniA provides a challenge for the efficient distribution of $\mathrm{Cu}$ to this enzyme, and for this reason, it appears that there is a high dependence on AccA for AniA biogenesis. SPR revealed a direct and high-affinity protein-protein interaction between AccA and AniA in

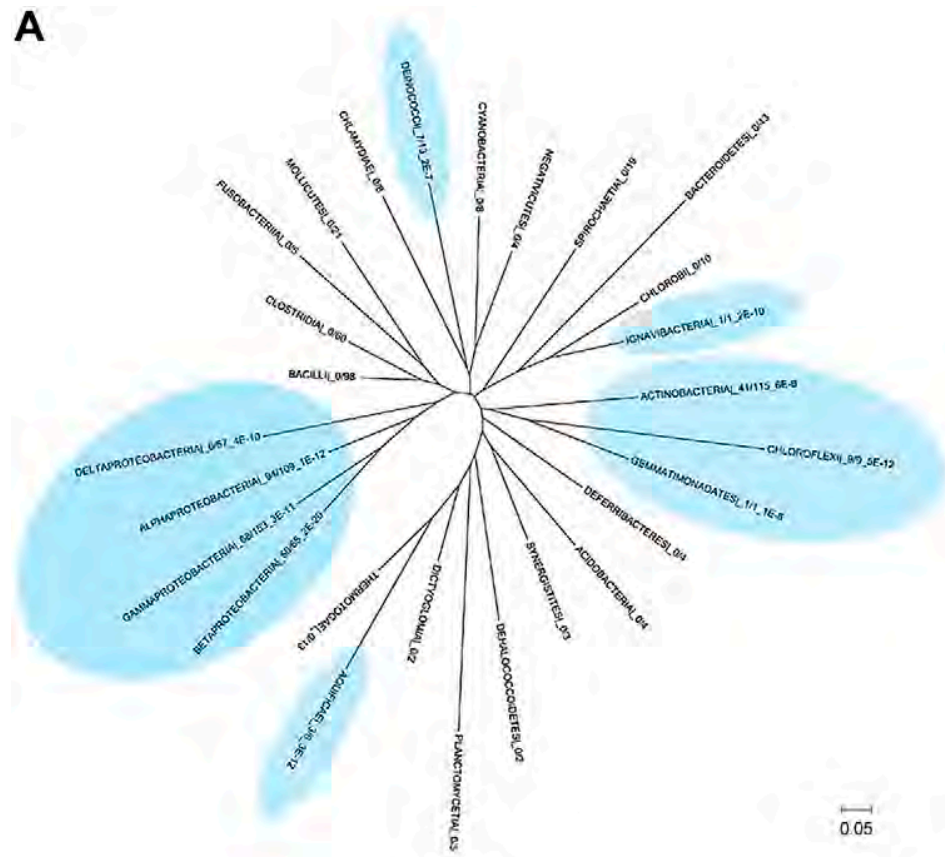

B
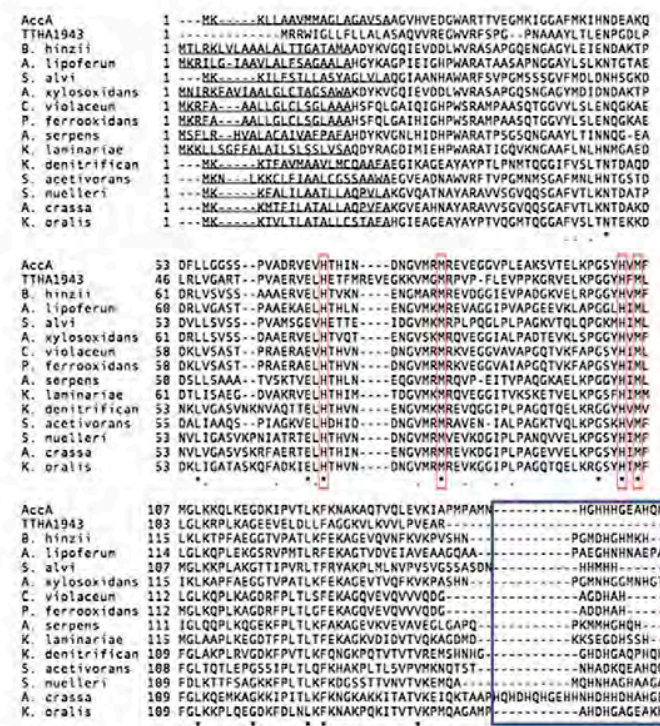

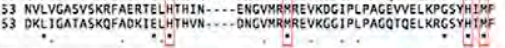

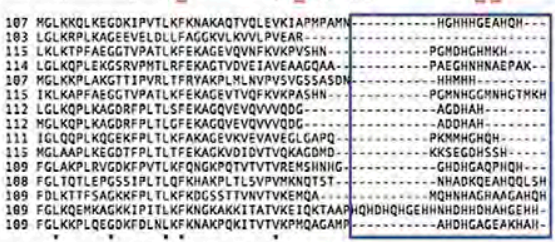

Figure 6. A) A phylogenetic tree of $16 \mathrm{~S}$ rRNA, with a representative from each of 23 bacterial phyla. The distribution of AccA across the bacterial domain is shown. B) A multiple alignment of AccA-like proteins from different bacteria. The N-terminal signal peptide is underlined. Red box: the conserved $\mathrm{Cu}$ (I) binding site; blue box: the C-terminal Cu (II) binding site. 


\begin{tabular}{|c|c|c|c|c|}
\hline Phylum & Frequency of a $c c A$ & $\begin{array}{c}\text { Geometric mean } \\
E \text { value }\end{array}$ & Positive taxa & Positive taxa $a c c A$ frequency \\
\hline Actinobacteria & $41 / 115$ & $6 \mathrm{E}-8$ & Various & \\
\hline Alphaproteobacteria & $94 / 109$ & IE-12 & Various & \\
\hline Aquificae & $3 / 6$ & $3 \mathrm{E}-12$ & Aquificaceae & $3 / 3$ \\
\hline Betaproteobacteria & $50 / 65$ & 2E-20 & Various & \\
\hline Chlorobi & $1 / 11^{a}$ & $2 \mathrm{E}-10$ & Ignavibacterium album & \\
\hline Chloroflexi & $9 / 11$ & $5 \mathrm{E}-12$ & Non-Dehalococcoides & $9 / 9$ \\
\hline Deinucoccus-Thermus & $7 / 13$ & $2 \mathrm{E}-7$ & Various & \\
\hline Deltaproteobacteria & $1 / 36^{a}$ & $3 \mathrm{E} 3^{a}$ & Stigmatella aurantiaca & \\
\hline Epsilonproteobacteria & $5 / 21$ & $2 \mathrm{E}-11$ & Campylobacteraceae & $5 / 6$ \\
\hline Gammaproteobacteria & $68 / 153$ & $3 \mathrm{E}-11$ & Non-Enterobacteriaceae & $68 / 108$ \\
\hline Gemmatimonadetes & $1 / 1^{a}$ & IE-6 & Gemmatimonas aurantiaca & \\
\hline
\end{tabular}

Patterns at the family, class, and order level were noted in Aquificae, Chloroflexi, Epsilonproteobacteria, and Gammaproteobacteria. ${ }^{a}$ Weak support for presence, such as when a single positive representative was found (Chlorobi, Deltaproteobacteria, and Gemmatimonadetes) and when the tblastn $E$ value was weak (Deltaproteobacteria).

vitro that is consistent with the view that, in pathogenesis, Neisseria has evolved as a dedicated biogenetic pathway for NirK. Apart from Neisseria, the AccA homolog was observed in some pathogenic bacteria but mainly in environmental bacteria that catalyze denitrification.

This study was funded in part by the Australian National Health and Medical Research Council Program Grant 565526 (to M.P.J. and A.G.M.) and Australian Research Council Discovery Project Grant 130103141 (to M.P.J.).

\section{REFERENCES}

1. Unemo, M., and Shafer, W. M. (2011) Antibiotic resistance in Neisseria gonorrhoeae: origin, evolution, and lessons learned for the future. Ann. N. Y. Acad. Sci. 1230, E19-E28

2. Hoehn, G. T., and Clark, V. L. (1992) Isolation and nucleotide sequence of the gene (aniA) encoding the major anaerobically induced outer membrane protein of Neisseria gonorrhoeae. Infect. Immun. 60, 4695-4703

3. Clark, V. L., Campbell, L. A., Palermo, D. A., Evans, T. M., and Klimpel, K. W. (1987) Induction and repression of outer membrane proteins by anaerobic growth of Neisseria gonorrhoeae. Infect. Immun. 55, 1359-1364

4. Knapp, J. S., and Clark, V. L. (1984) Anaerobic growth of Neisseria gonorrhoeae coupled to nitrite reduction. Infect. Immun. 46, 176-181

5. Barth, K. R., Isabella, V. M., and Clark, V. L. (2009) Biochemical and genomic analysis of the denitrification pathway within the genus Neisseria. Microbiology 155, 4093-4103

6. Falsetta, M. L., Steichen, C. T., McEwan, A. G., Cho, C., Ketterer, M. Shao, J., Hunt, J., Jennings, M. P., and Apicella, M. A. (2011) The composition and metabolic phenotype of Neisseria gonorrhoeae biofilms. Front. Microbiol. 2, 75

7. Echenique-Rivera, H., Muzzi, A., Del Tordello, E., Seib, K. L., Francois, P., Rappuoli, R., Pizza, M., and Serruto, D. (2011) Transcriptome analysis of Neisseria meningitidis in human whole blood and mutagenesis studies identify virulence factors involved in blood survival. PLoS Pathog. 7, e1002027

8. Boulanger, M. J., and Murphy, M. E. (2002) Crystal structure of the soluble domain of the major anaerobically induced outer membrane protein (AniA) from pathogenic Neisseria: a new class of copper-containing nitrite reductases. J. Mol. Biol. 315, 1111-1127

9. Hopper, A. C., Li, Y., and Cole, J. A. (2013) A critical role for the cccA gene product, cytochrome $\mathrm{c} 2$, in diverting electrons from aerobic respiration to denitrification in Neisseria gonorrhoeae. J. Bacteriol. 195, 2518-2529

10. Berks, B. C., Richardson, D. J., Robinson, C., Reilly, A., Aplin, R. T., and Ferguson, S. J. (1994) Purification and characterization of the periplasmic nitrate reductase from Thiosphaera pantotropha. Eur.J. Biochem. 220, 117-124

11. Gennis, R. B., Stewart, V. (1996) Respiration. In Escherichia coli and Salmonella: Cellular and Molecular Biology. (Neidhardt, F. C. III, R. C., Ingraham, J. L., Lin, E. C. C., Low, K. B., Magasanik, B., Reznikoff, W. S., Riley, M., Schaechter, M., and Umbarger, H. E., eds), pp. 217-261, ASM Press, Washington, D.C.

12. Shewell, L. K., Ku, S. C., Schulz, B. L., Jen, F. E., Mubaiwa, T. D., Ketterer, M. R., Apicella, M. A., and Jennings, M. P. (2013) Recombinant truncated AniA of pathogenic Neisseria elicits a nonnative immune response and functional blocking antibodies. Biochem. Biophys. Res. Commun. 431, 215-220

13. Ku, S. C., Schulz, B. L., Power, P. M., and Jennings, M. P. (2009) The pilin O-glycosylation pathway of pathogenic Neisseria is a general system that glycosylates AniA, an outer membrane nitrite reductase. Biochem. Biophys. Res. Commun. 378, 84-89

14. Virji, M., Makepeace, K., Peak, I. R., Ferguson, D. J., Jennings, M. P., and Moxon, E. R. (1995) Opc- and pilus-dependent interactions of meningococci with human endothelial cells: molecular mechanisms and modulation by surface polysaccharides. Mol. Microbiol. 18, 741-754

15. Apicella, M. A., Breen, J. F., and Gagliardi, N. C. (1978) Degradation of the polysaccharide component of gonococcal lipopolysaccharide by gonococcal and meningococcal sonic extracts. Infect. Immun. $\mathbf{2 0}$ 228-234

16. Warren, M. J., Roddam, L. F., Power, P. M., Terry, T. D., and Jennings, M. P. (2004) Analysis of the role of pglI in pilin glycosylation of Neisseria meningitidis. FEMS Immunol. Med. Microbiol. 41, 43-50

17. Ieva, R., Alaimo, C., Delany, I., Spohn, G., Rappuoli, R., and Scarlato, V. (2005) CrgA is an inducible LysR-type regulator of Neisseria meningitidis, acting both as a repressor and as an activator of gene transcription. J. Bacteriol. 187, 3421-3430

18. Steichen, C. T., Shao, J. Q., Ketterer, M. R., and Apicella, M. A. (2008) Gonococcal cervicitis: a role for biofilm in pathogenesis. J. Infect. Dis. 198, 1856-1861

19. Van der Ley, P., Kramer, M., Steeghs, L., Kuipers, B., Andersen, S. R., Jennings, M. P., Moxon, E. R., and Poolman, J. T. (1996) Identification of a locus involved in meningococcal lipopolysaccharide biosynthesis by deletion mutagenesis. Mol. Microbiol. 19, $1117-1125$

20. DuMont, A. L., Yoong, P., Day, C. J., Alonzo III, F., McDonald, W. H., Jennings, M. P., and Torres, V. J. (2013) Staphylococcus aureus LukAB cytotoxin kills human neutrophils by targeting the CD11b subunit of the integrin Mac-1. Proc. Natl. Acad. Sci. USA 110, 10794-10799

21. Beauchamp, C., and Fridovich, I. (1971) Superoxide dismutase: improved assays and an assay applicable to acrylamide gels. Anal. Biochem. 44, 276-287

22. Camacho, C., Coulouris, G., Avagyan, V., Ma, N., Papadopoulos, J., Bealer, K., and Madden, T. L. (2009) BLAST+: architecture and applications. BMC Bioinformatics 10, 421

23. Tamura, K., Stecher, G., Peterson, D., Filipski, A., and Kumar, S. (2013) MEGA6: Molecular Evolutionary Genetics Analysis version 6.0. Mol. Biol. Evol. 30, 2725-2729 
24. Householder, T. C., Fozo, E. M., Cardinale, J. A., and Clark, V. L. (2000) Gonococcal nitric oxide reductase is encoded by a single gene, norB, which is required for anaerobic growth and is induced by nitric oxide. Infect. Immun. 68, 5241-5246

25. Aspholm, M., Aas, F. E., Harrison, O. B., Quinn, D., Vik, A., Viburiene, R., Tønjum, T., Moir, J., Maiden, M. C., and Koomey, M. (2010) Structural alterations in a component of cytochrome c oxidase and molecular evolution of pathogenic Neisseria in humans. PLoS Pathog. 6, e1001055

26. Seib, K. L., Jennings, M. P., and McEwan, A. G. (2003) A Sco homologue plays a role in defence against oxidative stress in pathogenic Neisseria. FEBS Lett. 546, 411-415

27. Seib, K. L., Tseng, H.J., McEwan, A. G., Apicella, M. A., and Jennings, M. P. (2004) Defenses against oxidative stress in Neisseria gonorrhoeae and Neisseria meningitidis: distinctive systems for different lifestyles. J. Infect. Dis. 190, 136-147

28. Bordoli, L., Kiefer, F., Arnold, K., Benkert, P., Battey, J., and Schwede, T. (2009) Protein structure homology modeling using SWISSMODEL workspace. Nat. Protoc. 4, 1-13

29. Abriata, L. A., Banci, L., Bertini, I., Ciofi-Baffoni, S., Gkazonis, P., Spyroulias, G. A., Vila, A. J., and Wang, S. (2008) Mechanism of Cu (A) assembly. Nat. Chem. Biol. 4, 599-601

30. Banci, L., Bertini, I., Ciofi-Baffoni, S., Katsari, E., Katsaros, N., Kubicek, K., and Mangani, S. (2005) A copper(I) protein possibly involved in the assembly of CuA center of bacterial cytochrome c oxidase. Proc. Natl. Acad. Sci. USA 102, 39943999

31. Xiao, Z., and Wedd, A. G. (2010) The challenges of determining metal-protein affinities. Nat. Prod. Rep. 27, 768-789

32. Robinson, N. J., and Winge, D. R. (2010) Copper metallochaperones. Annu. Rev. Biochem. 79, 537-562

33. Teitzel, G. M., Geddie, A., De Long, S. K., Kirisits, M. J., Whiteley, M., and Parsek, M. R. (2006) Survival and growth in the presence of elevated copper: transcriptional profiling of copper-stressed Pseudomonas aeruginosa. J. Bacteriol. 188, $7242-7256$

34. Rowland, J. L., and Niederweis, M. (2012) Resistance mechanisms of Mycobacterium tuberculosis against phagosomal copper overload. Tuberculosis (Edinb.) 92, 202-210

35. Kim, B. E., Nevitt, T., and Thiele, D.J. (2008) Mechanisms for copper acquisition, distribution and regulation. Nat. Chem. Biol. 4, 176-185

36. Mattle, D., Sitsel, O., Autzen, H. E., Meloni, G., Gourdon, P., and Nissen, P. (2013) On allosteric modulation of P-type Cu(+)-ATPases. J. Mol. Biol. 425, 2299-2308

37. Ekici, S., Yang, H., Koch, H. G., and Daldal, F. (2012) Novel transporter required for biogenesis of cbb3-type cytochrome c oxidase in Rhodobacter capsulatus. MBio 3, e00293-11

38. Djoko, K. Y., Franiek, J. A., Edwards, J. L., Falsetta, M. L., Kidd, S. P., Potter, A. J., Chen, N. H., Apicella, M. A., Jennings, M. P., and McEwan, A. G. (2012) Phenotypic characterization of a copA mutant of Neisseria gonorrhoeae identifies a link between copper and nitrosative stress. Infect. Immun. 80, 1065-1071

39. Heaton, D., Nittis, T., Srinivasan, C., and Winge, D. R. (2000) Mutational analysis of the mitochondrial copper metallochaperone Cox17. J. Biol. Chem. 275, 37582-37587

40. Serventi, F., Youard, Z. A., Murset, V., Huwiler, S., Bühler, D., Richter, M., Luchsinger, R., Fischer, H. M., Brogioli, R., Niederer, M., and Hennecke, H. (2012) Copper starvation-inducible protein for cytochrome oxidase biogenesis in Bradyrhizobium japonicum. J. Biol. Chem. 287, 38812-38823

41. Battistoni, A., Pacello, F., Mazzetti, A. P., Capo, C., Kroll, J. S., Langford, P. R., Sansone, A., Donnarumma, G., Valenti, P., and Rotilio, G. (2001) A histidine-rich metal binding domain at the $\mathrm{N}$ terminus of $\mathrm{Cu}, \mathrm{Zn}$-superoxide dismutases from pathogenic bacteria: a novel strategy for metal chaperoning. J. Biol. Chem. 276,30315-30325

Received for publication February 6, 2015. Accepted for publication May 18, 2015. 